\title{
Front Matter: Volume 11642
}

, "Front Matter: Volume 11642," Proc. SPIE 11642, Photons Plus Ultrasound: Imaging and Sensing 2021, 1164201 (12 May 2021); doi: 10.1117/12.2596620

SPIE. Event: SPIE BiOS, 2021, Online Only 


\section{PROGRESS IN BIOMEDICAL OPTICS AND IMAGING}

\section{Photons Plus Ultrasound: Imaging and Sensing 2021}

Alexander A. Oraevsky

Lihong V. Wang

Editors

6-11 March 2021

Online Only, United States

Sponsored by

SENO Medical Instruments, Inc. (United States)

Published by

SPIE 
The papers in this volume were part of the technical conference cited on the cover and title page. Papers were selected and subject to review by the editors and conference program committee. Some conference presentations may not be available for publication. Additional papers and presentation recordings may be available online in the SPIE Digital Library at SPIEDigitalLibrary.org.

The papers reflect the work and thoughts of the authors and are published herein as submitted. The publisher is not responsible for the validity of the information or for any outcomes resulting from reliance thereon.

Please use the following format to cite material from these proceedings:

Author(s), "Title of Paper," in Photons Plus Ultrasound: Imaging and Sensing 2021, edited by Alexander A. Oraevsky, Lihong V. Wang, Proceedings of SPIE Vol. 11642 (SPIE, Bellingham, WA, 2021) Seven-digit Article CID Number.

ISSN: $1605-7422$

ISSN: 2410-9045 (electronic)

ISBN: 9781510641198

ISBN: 9781510641204 (electronic)

Published by

SPIE

P.O. Box 10, Bellingham, Washington 98227-0010 USA

Telephone +1 3606763290 (Pacific Time) · Fax +1 3606471445

SPIE.org

Copyright @ 2021, Society of Photo-Optical Instrumentation Engineers.

Copying of material in this book for internal or personal use, or for the internal or personal use of specific clients, beyond the fair use provisions granted by the U.S. Copyright Law is authorized by SPIE subject to payment of copying fees. The Transactional Reporting Service base fee for this volume is $\$ 21.00$ per article (or portion thereof), which should be paid directly to the Copyright Clearance Center (CCC), 222 Rosewood Drive, Danvers, MA 01923. Payment may also be made electronically through CCC Online at copyright.com. Other copying for republication, resale, advertising or promotion, or any form of systematic or multiple reproduction of any material in this book is prohibited except with permission in writing from the publisher. The CCC fee code is $1605-$ $7422 / 21 / \$ 21.00$.

Printed in the United States of America by Curran Associates, Inc., under license from SPIE.

Publication of record for individual papers is online in the SPIE Digital Library.

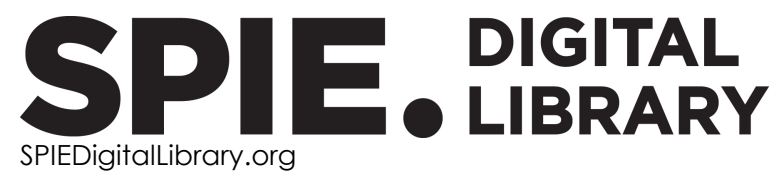

Paper Numbering: Proceedings of SPIE follow an e-First publication model. A unique citation identifier (CID) number is assigned to each article at the time of publication. Utilization of CIDs allows articles to be fully citable as soon as they are published online, and connects the same identifier to all online and print versions of the publication. SPIE uses a seven-digit CID article numbering system structured as follows:

- The first five digits correspond to the SPIE volume number.

- The last two digits indicate publication order within the volume using a Base 36 numbering system employing both numerals and letters. These two-number sets start with 00, 01, 02, 03, 04, 05, 06, 07, 08, 09, OA, OB ... 0Z, followed by 10-1Z, 20-2Z, etc. The CID Number appears on each page of the manuscript. 


\section{Contents}

\section{AWARD CANDIDATES: ORAL PRESENTATIONS}

1164209 In vivo applications of raster-scan optoacoustic angiography [11642-79]

$116420 \mathrm{~A}$ Whole-body visualization of nanoagent kinetics in mice with flash scanning volumetric optoacoustic tomography [11642-58]

$11642 O B \quad$ Seamlessly integrated multi-modal imaging system through transparent ultrasound transducer in vivo [11642-31]

$116420 \mathrm{C}$ Feasibility study on concurrent optoacoustic tomography and magnetic resonance imaging [11642-43]

11642 OD 3D optoacoustic tomography via coded acoustic apertures [11642-17]

$11642 \mathrm{OE}$ Three-dimensional photoacoustic computed tomography for preclinical research and clinical translation [1 1642-139]

AWARD CANDIDATES: POSTERS

$116420 \mathrm{G}$ Breast imaging using an LED-based photoacoustic and ultrasound imaging system: a proof-of-concept study [11642-89]

$116420 \mathrm{~J}$ Comparison of various photoacoustic imaging reconstruction algorithms under realistic scenarios: a simulation study [11642-20]

$116420 \mathrm{M}$ Label-free photoacoustic expansion histopathology with enhanced temporal and spatial resolution [11642-30]

11642 ON X-ray induced acoustic computed tomography with a conventional $x$-ray contrast agent [11642-5]

1164200 Clinical photoacoustic computed tomography of breast cancer treated with neoadjuvant chemotherapy (Elseveier Best Poster Award) [1 1642-140]

\section{CLINICAL APPLICATIONS}

11642 OP 3D multi-structural foot imaging using dual-modal photoacoustic and ultrasound imaging [11642-101]

$116420 Q \quad$ Applicability of photoacoustic microscopy to quantitative photoaging evaluation [11642-111] 
11642 OR Quantitative evaluation of skin photoaging mechanisms using multi-wavelength analysis of photoacoustic images [11642-119]

11642 OT Parking sensor-inspired approach to photoacoustic-guided hysterectomy demonstrated with human cadavers [11642-103]

TOWARDS CLINICAL APPLICATIONS

1164210 Photoacoustic differentiation of cortical from cancellous bone in the lumbar vertebrae of an intact human cadaver to prevent bone breaches during spinal fusion surgeries [11642-104]

IMAGE RECONSTRUCTION

1164213 Spatiotemporal antialiasing in photoacoustic computed tomography [11642-142]

1164215 Ultrasound localized microscopy-based spatial prior for photoacoustic reconstruction with a linear transducer array [11642-38]

1164218 Spatially distributed sensor array calibration for photoacoustic imaging [11642-18]

SIGNAL PROCESSING AND ANALYSIS

$116421 \mathrm{C}$ Generalized contrast-to-noise ratio as a metric of photoacoustic image quality [11642-107]

$116421 \mathrm{~K}$ In vivo demonstration of reflection artifact reduction in LED-based photoacoustic imaging using deep learning [1 1642-110]

QUANTITATIVE AND FUNCTIONAL IMAGING

$116421 \mathrm{P} \quad$ Optical fluence-compensated functional optical-resolution photoacoustic microscopy

[11642-40]

11642 is Photoacoustic reconstruction from photothermal measurements [11642-170]

ULTRASONIC DETECTION

11642 lV Polymer-based spherical matrix array for high resolution real-time volumetric optoacoustic micro-angiography [11642-115]

iv 
11642 IW An optically-transparent transducer with a high-NA and wide-bandwidth for photoacoustic microscopy (PAM) [11642-12]

1164220 Transparent ultrasound transducers for multiscale photoacoustic imaging [1 1642-108]

1164224 A new high-frequency photoacoustic sensing probe (PAS) using silicon acoustic delay lines (SADLs) [11642-146]

\section{NEW METHODS IN PHOTOACOUSTICS}

1164227 Localization optoacoustic tomography (LOT) in vivo with particles smaller than red blood cells [11642-77]

1164228 Validation of eyelids as acoustic receiver locations for photoacoustic-guided neurosurgery [11642-138]

11642 2C Microscale photoacoustic spectroscopy using integrated photonics for lab-on-chip applications [11642-102]

$116422 \mathrm{E} \quad$ Deep learning enabled real-time photoacoustic tomography system via single data acquisition channel [11642-69]

\section{SMALL ANIMAL IMAGING AND THERAPEUTICS}

$116422 \mathrm{H} \quad$ Assessment of murine heart function post myocardial infraction with volumetric optoacoustic tomography [11642-117]

$1164221 \quad$ Ultrasound and LED-based photoacoustic system for preclinical imaging of liver fibrosis [11642-52]

$116422 \mathrm{~K}$ Concurrent in vivo tumor ablation and real-time optoacoustic monitoring with a pulsed 1064 nm laser source [1 1642-78]

$116422 \mathrm{~L}$ Transmission-reflection optoacoustic ultrasound (TROPUS) imaging of mammary fumors [11642-59]

$116422 \mathrm{~N}$ Optimization of light and sound delivery for in vivo whole-brain optoacoustic angiography of rodents [11642-116]

\section{MICROSCOPY}

$116422 \mathrm{U} \quad$ Wide-field photoacoustic microscopy of oxygen saturation at 1-MHz A-line rate [11642-39]

1164230 Efficient model-based reconstruction framework for acoustic-resolution optoacoustic microscopy [11642-99] 
POSTER SESSION: CLINICAL APPLICATIONS

$1164234 \quad$ Handheld photoacoustic detector and its potential application for sentinel lymph node sensing [11642-22]

POSTER SESSION: IMAGE RECONSTRUCTION

1164235 Generative adversarial network-based photoacoustic image reconstruction from bandlimited and limited-view data [1 1642-54]

$116423 \mathrm{~A}$ Improvement of linear array based real-time photoacoustic imaging using Pth root coherence factor [11642-137]

$116423 B \quad$ A photoacoustic image reconstruction method for point source recovery [11642-61]

11642 3D Improvement of delay and sum beamforming photoacoustic imaging based on delaymultiply-sum-to-standard-deviation-factor [11642-132]

$116423 \mathrm{E} \quad$ Application of deep learning to improve tangential resolution in photoacoustic tomography [11642-26]

$116423 \mathrm{H} \quad$ An iterative method of light fluence distribution estimation for quantitative photoacoustic imaging [1 1642-143]

POSTER SESSION: SIGNAL PROCESSING AND ANALYSIS

1164231 Image quality enhancement for LED-based photoacoustic imaging [1 1642-1 14]

11642 3J Deep learning denoising method of photoacoustic microscopy [11642-157]

11642 3K A broadband PA signal enhancement method with morphological frequency convolution for photoacoustic tomography [11642-46]

$116423 \mathrm{M} \quad$ Enhanced spectral unmixing scheme with unknown target spectral signature in multispectral photoacoustic tomography [11642-112]

$116423 \mathrm{~N}$ The limited-view compensation of photoacoustic tomography via deep learning [1 1642-62]

1164230 Investigation of optical absorption induced temperature change and amplification of photoacoustic signal of contrast dye [11642-160]

$116423 Q \quad$ Improved photoacoustic brain imaging using a deep learning protocol [11642-124]

$116423 R \quad$ Vortex-beam photoacoustic microscopy for enhancing the depth of field [11642-175] 
1164235 Spectrum analysis of photoacoustic signal based on COMSOL [11642-174]

POSTER SESSION: NEW METHODS IN PHOTOACOUSTICS AND ACOUSTO-OPTICS

11642 3T X-ray induced acoustic imaging using a synchrotron [11642-131]

11642 3V Optimizing acoustic detection for deep-tissue LED-based photoacoustic imaging [11642-88]

$116423 Y$ Research on the photon transmission and heat transfer between pulsed laser and human brain based on COMSOL [1 1642-150]

1164240 Towards the development of backing layer for piezoelectric micromachined ultrasound transducers [11642-136]

$1164241 \quad$ Detecting and evaluating vulnerable artery plaque with handheld photoacoustic imaging system [11642-47]

\section{POSTER SESSION: MICROSCOPY}

$1164245 \quad$ High-speed wide-field photoacoustic microscopy with enhanced sensitivity [1 1642-28]

$1164246 \quad$ Efficient image compression for high-throughput photoacoustic microscopy systems [1 1642-125]

$1164247 \quad$ Improving out-of-focus resolution in acoustic resolution photoacoustic microscopy using deep learning [1 1642-42]

$1164248 \quad$ Virtual Airy-beam photoacoustic microscopy for large volumetric imaging based on K-Wave matlab toolbox [1 1642-152]

1164249 Optimal design of conical concave acoustic lens for large volumetric photoacoustic microscopy based on ray tracing [11642-156]

$116424 \mathrm{~A} \quad$ Simulation platform of compressed sensing photoacoustic tomography based on k-wave [1 1642-153]

11642 4B Development of fast photoacoustic microscopy system for small animal brain imaging [11642-127]

11642 4D Virtual Bessel-beam photoacoustic microscopy with extended depth of field using k-Wave [1 1642-149] 
POSTER SESSION: SMALL ANIMAL IMAGING AND THERAPEUTICS

$116424 G \quad$ A study of laser irradiation-aided sonothrombolysis using gold nanoparticles-coated microbubbles via combined ultrasound (US) and photoacoustic (PA) imaging [1 1642-64]

$116424 \mathrm{H} \quad$ A study of the effect of microbubbles with different gas cores and saline solution on microbubbles-assisted sonothrombolysis via combined ultrasound and photoacoustic imaging [1 1642-68]

$116424 \mathrm{I} \quad$ Fundamental study for detection of anisakis by photoacoustic imaging [1 1642-80]

POSTER SESSION: TOWARD QUANTITATIVE IMAGING AND STANDARDISATION

$116424 \mathrm{P} \quad$ Study the effect of the skull in light illumination and ultrasound detection paths in transcranial photoacoustic imaging [11642-126]

POSTER SESSION: ACOUSTO-OPTICS

$116424 R \quad$ Plane wave acousto-optic imaging in reflection mode geometry [11642-2] 